\title{
A História da Música em Questão: Uma Reflexão Metodológica*
}

\author{
Vanda Lima Bellard Freire
}

Uma reflexão sobre os encaminhamentos metodológicos mais usualmente empregados na prática histórica referente à atividade musical é o propósito desta conferência, mas tem sido, também, o propósito principal de toda uma trajetória profissional.

O tema desta conferência surgiu, provavelmente, no decorrer do próprio curso de Graduação, diante da perplexidade com a profusão de nomes de autores, obras e biografias a serem memorizados sem o desenvolvimento de qualquer prática reflexiva. Textos áridos eram lidos e a ênfase desses textos incidia no enfileiramento cronológico de fatos "musicais", o que incluía até dados pessoais de compositores "maiores" e o apontar de "influências", ou causas e conseqüências, para este ou aquele procedimento estético. Posteriormente, já no exercício do magistério superior, na disciplina História da Música, o impasse persistiu, pois a escolha de bibliografia interessante, teoricamente consistente, tem sido tarefa dificil.

A bibliografia sobre História da Música, ainda que revestida de considerações sobre o contexto em que as obras foram geradas por seus autores, essencialmente continua enfatizando, na quase totalidade dos casos, a sucessão cronológica, a derivação causal de processos estéticos, ainda que enriquecidos por exemplos obti-

\footnotetext{
* Resumo da Conferência proferida no concurso para Professor Titular de História da Música da Universidade Federal do Rio de Janeiro.
} 
dos da análise de obras. A dificuldade de estruturar um caminho teoricamente consistente para a elaboração de um discurso sobre a História da Música, seja no trabalho em classe, seja na orientação ou na estruturação de pesquisas, levou a que se concentrassem os esforços na busca de um referencial teórico-metodológico satisfatório.

Os principais caminhos trilhados nesse questionamento serão expostos nesta conferência, assim como a concepção teórico-metodológica a que se chegou, concepção essa que visa à proposição de um caminho alternativo - e, pretensamente, mais consistente e condizente - para a elaboração do relato histórico sobre a música.

Inúmeras têm sido as concepções de História na trajetória das sociedades humanas. A concepção que, neste trabalho, toma-se como base é a de que História é um relato interpretativo, feito por um sujeito histórico, ele próprio impregnado de significados e percepções inerentes a seu tempo, e dos quais ele nunca poderá se despir inteiramente... Seu relato, sua visão do passado, trará inevitavelmente essa marca.

Nessas afirmativas iniciais, colocam-se os primeiros aspectos do questionamento aqui apresentado - relato interpretativo, significados, visão histórica do historiador...

A ciência em geral - e não somente a História - já viveu a ilusão da neutralidade e da objetividade absoluta, como se fosse possível ao homem deixar de o ser (homem histórico), para se tornar apenas "cientista neutro". As ciências sociais - por motivos óbvios - têm encabeçado a discussão dessa ilusão e é possível, aqui, nesta trajetória de busca, alinharmo-nos com Nicole Loraux em seu artigo "O Elogio do Anacronismo" (1992), ao defender a prática controlada do anacronismo, ou seja, reconhecer a impossibilidade de suspender as próprias categorias e pôr-se (o historiador) à escuta do tempo, ultrapassando o tempo da narração ordenada, que é constituído de "ilhotas de imobilidade".

De que tempo tem sido feita a história? Que tipo de relato tem resultado dessa prática? 
A História, tradicionalmente, tem abordado o "tempo da narração ordenada", de que falam tantos autores contemporâneos, com denominações diversas - narração ordenada, tempo seqüencial, linear, tempo identitário, tempo causal, tempo determinista...

A História da Música não tem sido diferente - ela tem estruturado seu relato nessa perspectiva de tempo; e tem tido como objeto de estudo não a música, mas os artistas, as obras; os estilos, as estruturas, as conjunturas etc. A História - relato do Homem sobre o Homem - não se faz numa abordagem individualística: artistas, indivíduos, só significam na História quando imersos no social-histórico a que pertencem.

A História da Arte, como História dos artistas, segundo Hadjinicolaou (1989), oculta a relação profunda da arte com a ideologia, ou seja, tenta explicar uma obra particular ou a produção global de um artista pela sua individualidade - seja como explicação psicológica (personalidade do artista), como explicação psicanalítica (a partir do inconsciente do artista) ou pelo "meio" (isto é, pelo ambiente do artista). Inverte-se, nos três casos, a relação indivíduo-História, ao se buscar explicar a História - fenômeno social, necessariamente coletivo - a partir do indivíduo, ignorando a sua imersão no universo ideológico, no social-histórico a que pertence. O indivíduo puro e simples é invisível enquanto tal na perspectiva histórica.

A História da Música tem sido praticada, também, como História da Cultura, História do Espírito ou História da Sociedade. Todas estas concepções trabalham a arte como "sintoma", como manifestação de "outra coisa" (Espírito, Cultura, Sociedade) e não como elemento integrante da construção da própria História. Desconhecem, também, a heterogeneidade e descontinuidade das sociedades, das ideologias que, nelas, se imbricam.

A pretensa uniformidade - Espírito único, que rege a História da humanidade e se "reflete" nas obras de arte, a "Cultura" ou a Sociedade una e homogênea - encobre as contradições do fazer e do pensar sociais, predetermina a História - já que admite um significado uno, superior, que se "manifesta" em obras particulares - e elimina a perspectiva da arte como agente da História. 
A História não é o somatório de obras particulares; e essa inversão de perspectiva inviabiliza o relato histórico como interpretação do fazer-dizer-representar de uma sociedade, que é essencialmente coletivo. A História das formas incide nesses aspectos e em outros igualmente importantes, como a superação do binômio forma-conteúdo (promovendo a supervalorização do primeiro) e a conseqüente autonomização da forma.

Estudos que analisam ou comparam formas de obras de arte não são estudos históricos, ainda que possam servir como elemento primário para a elaboração de efetivos estudos históricos. Não se pode explicar as formas na arte esvaziando-as de seu conteúdo, assim como não se pode explicar a forma de uma obra pela possível analogia ou "influência" de uma forma sobre outra, de uma obra sobre outra... Forma é modelagem de um conteúdo - significado social - e só nessa perspectiva ela pode adquirir qualquer relevância histórica.

História das formas isoladas traz, subjacente, a concepção de autogênese das formas, como se elas tivessem "vida" e "evolução" autônomas, despe as formas do conteúdo que viabilizam, e somente em interação com o qual elas existem e significam, estabelece elos causais e deterministas entre formas e elabora uma falsa perspectiva histórica, pois que dissociada dos significados coletivos.

A História das estruturas procura englobar as formações artísticas particulares em concepções estruturais portadas por povos ou culturas. Ao tentar retornar à perspectiva coletiva, essa modalidade de História retoma as concepções de homogeneidade, de Espírito uno e de predeterminação na arte, pois essas concepções estruturais globais preexistem ao fazer artístico, são unas e unidirecionadas, e desconhecem, portanto, as contradições, as incertezas, as indeterminidades do processamento social...

A História da Arte como História das obras de arte particulares corresponde a uma concepção que, no dizer de Hadjinicolaou (1989), considera como única realidade existente a obra concreta e singular, e que o dever do historiador é reconstituir seu estado original, datá-la e analisá-la exaustivamente. Se lhe acontece des- 
cobrir "influências", ele as retira da descrição comparativa das formas, o que, segundo o autor, tem fornecido tema para muitas teses de doutorado. Resgata-se a concepção de "arte pela arte" ao analisarem-se formas estéreis, despidas de conteúdo social, disfarçadas, contudo, sob brilhantes e penetrantes análises de forma. E tentase, também, inverter a perspectiva da História, partindo-se de explicações particulares...

A História da Arte, a partir da noção de estilo - entendido como combinação específica de elementos formais e temáticos, combinação que é uma das formas da Ideologia Global de uma classe (Hadjinicolaou, 1989) - abre algumas portas para que se evitem os equívocos das abordagens anteriores, pois busca o coletivo (estilo como expressão ideológica de uma classe social), evita a particularização e engloba, necessariamente, a noção de significado social.

É a partir dessa concepção de estilo que Hadjinicolaou propõe como objeto da História da Arte a Ideologia Imagética, definindo-a como "uma combinação específica de elementos formais e temáticos da imagem, através da qual os homens exprimem a maneira como vivem as suas relações com as suas condições de existência, combinação que constitui uma das formas particulares da Ideologia Global de uma classe" (Hadjinicolaou, 1989, p. 102). O autor estabelece, assim, uma relação dialética entre o geral e o particular, e admite a análise de obras (particulares) como passos para a explicitação da Ideologia Imagética, que é coletiva (geral), sobreindividual e supranacional, categoria central da História da Arte.

Os aspectos positivos da concepção de Hadjinicolaou pareceram, durante algum tempo, ter trazido uma solução, ou um apontar de caminho, para a questão da História da Música, apesar dos problemas evidentes que constituíram a transposição, para a música, do conceito de Ideologia Imagética. Contudo, a análise mais aprofundada dessa concepção apresentou novos impasses, pois não elimina a concepção de predeterminação da arte ao admitir a determinação do nível ideológico pelo nível das relações de produção. Ou seja, ao admitir o econômico, expresso nas lutas de classe 
(e suas ideologias) como causa e motor da História, estabelece um determinismo que já não é de forma sobre forma, ou de um Espírito sobre as estruturas, mas do econômico sobre a arte, um econômico autonomizado e definidor dos rumos sociais (e artísticos, como instância que a arte é do social). Além disso, mantém a concepção linear do tempo - tempo cronológico - como primordial na elaboração de uma História da Arte.

E aqui retomamos a questão do tempo, com a finalidade de começar a explicitar á concepção teórico-metodológica pretendida e apresentada no início desta conferência.

Vamos defender a adoção de uma concepção não-linear do tempo como instância primordial na construção de uma História da Música; e vamos defender, também, a não-determinidade/causalidade como categoria aplicável a essa mesma construção. E, não linearmente, as duas concepções serão abordadas intrincadamente...

$\mathrm{O}$ tempo tem sido concebido de diferentes maneiras pela humanidade e concepções não-lineares, nessa trajetória, não constituem novidade.

Tempo absoluto e tempo relativo são tomados por Newton como fundamento da sua mecânica. Na filosofia kantiana, o tempo é reduzido à sucessão causal; e, em Hegel, como intuição do tempo ou intuição do devir. Bergson, na filosofia moderna, reapresentou a formulação de Santo Agostinho', contrapondo-se ao conceito científico do tempo. Segundo ele, o tempo da ciência é um tempo especializado que, portanto, não tem nenhuma das características que a consciência reconhece como próprias do tempo.

Para Heidegger, numa linha de concepção do tempo como estrutura da possibilidade, o tempo é interpretado em termos de possibilidade ou projetação: o tempo é originariamente ad-vir. E admite, a partir dai, duas modalidades: o autêntico e o inautêntico. Tempo autêntico é o tempo originário, finito, próprio da existência. O tempo inautêntico é aquele da existência banal, em que se torna uma sucessão infinita de instantes.

Entre as contribuições mais significativas de Heidegger ao conceito de tempo, pode ser destacada a concepção de possibilidade, sendo o tempo não mais reconduzido a uma estrutura neces- 
sária, como a ordem causal, mas como estrutura de possibilidade: o tempo não é uma ordem necessária, mas a possibilidade de muitas ordens. ${ }^{2}$

Bachelard é outro filósofo que enfoca a temática do tempo, concebendo-o, numa abordagem mais psicológica, como dotado de várias dimensões. O tempo, segundo ele, só aparece como contínuo graças à superposição de muitos tempos independentes (Bachelard, 1988).

Deleuze, em Lógica do Sentido, enfatiza a abordagem do tempo segundo duas leituras opostas: a de Cronos e a de Aion. De acordo com Cronos, só o presente existe no tempo. Passado, presente e futuro não são três dimensões do tempo; só o presente preenche o tempo; o passado e o futuro são duas dimensões relativas ao presente no tempo. De acordo com Aion, somente o passado e o futuro insistem ou subsistem no tempo.

A relação tempo/significado transparece nas concepções de tempo aqui mencionadas e talvez de forma mais especial em Deleuze, pela referência mais explícita à linguagem, como instância decorrente do tempo-Aion, tempo esse que não é a única concepção temporal possível - a concepção dual ou múltipla do tempo emerge, não só em Deleuze, mas em toda a história da humanidade.

E aqui retomamos o questionamento da História da Música, tentando resgatá-la a partir da proposta enunciada de que ela se funde numa concepção de tempo não-linear.

Que tempo é esse, então, que deve subsidiar o relato dessa História? É o tempo-criação, o tempo-significado, o tempo instituinte, o tempo não redutivel à concepção linear, unidirecional. É o tempo regido pelo imaginário de uma sociedade, imaginário esse que, na concepção de Castoriadis, preside a elaboração de significados e sentidos numa sociedade, que, portanto, não pode ser explicada a partir da determinação do econômico (Castoriadis, 1991).

E será que, efetivamente, os rumos da História podem ser lidos como predeterminados pelo econômico, como se o econômico não fosse, ele mesmo, fruto da criação humana? E sobretudo na 
história da Arte, e mais especialmente na História da Música, será possivel reduzir a expressão artística às determinações da infraestrutura? Se a arte é criação, é proposição de formas e, conseqüentemente, de sentidos, será possivel aprisioná-la na unidirecionalidade temporal do tempo linear, regido e predeterminado pelas relações de produção? Qual seria a função da arte nessa perspectiva? Apenas "refletir" as relações econômicas, as lutas de classe?

A arte é sobretudo criação. É a constituição do novo e isso não pode ser apreendido por uma ótica determinista, que acorrenta a criação à relação causal, seja ela econômica ou de outra natureza.

A arte é uma expressão simbólica e, segundo Castoriadis, só existe História porque os homens se comunicam e cooperam num meio simbólico, sendo que esse simbolismo é, ele próprio, criado. “A História só existe na e pela 'linguagem' (todas as espécies de linguagem), mas essa linguagem ela se dá, ela constitui, ela transforma" (Castoriadis, 1991, p. 168).

A questão essencial da História é a da gênese do sentido, da produção de significados e significantes, da constituição de novos sistemas simbólicos, questão essa que não pode ser apreendida pela ótica estrita do tempo-linear-causal, mas do tempo-criação-significação. Tal como na oposição Aion-Cronos descrita por Deleuze, não se trata de negar o tempo cronológico, o tempo sucessão, o tempo matemático, pois o tempo-criação-significação que aqui se propõe como prioritário para uma abordagem da História da Música não elimina a perspectiva do tempo-calendário, demarcação que toda sociedade, segundo parâmetros diferentes, faz de seu tempo.

Mas, como reduzir a pluralidade de sentidos e de temporalidades simbolizadas na música, a uma rede causal de sucessões lineares num tempo predeterminado?

Na verdade, coloca-se, aqui, o tempo em dois níveis na História da Música: na rede simbólica, que constitui a própria música, objeto dessa História, e no relato que se faz sobre ela quando se faz História da Música. E, em ambos os casos, é o tempo-criação significação - e não o tempo calendário - que permite uma melhor 
aproximação do fenômeno musical e de sua trajetória, plena de significados e de sentidos, plena de acasos, plena de concepções reversíveis de tempo, plena de novas propostas de ordenações, plena de indeterminações...

O imaginário da sociedade considerada é o elemento que, segundo Castoriadis, "dá à funcionalidade de cada sistema institucional sua orientação específica, que sobredetermina a escolha e as conexões das redes simbolicas, criação de cada época histórica, sua singular maneira de viver, ver e fazer sua própria existência" (Castoriadis, 1991, p. 175). O imaginário é o estruturante originário da sociedade, é o significado-significante central, suporte das articulações, das distinções, dos valores. O imaginário é a fonte das significações específicas que cada sociedade elabora, o que inclui as significações propostas e portadas pela arte. É o imaginário que confere unidade à sociedade, permitindo que ela seja não um caos, mas uma pluralidade ordenada.

A percepção dessa pluralidade, dessa heterogeneidade inerente às sociedades e, conseqüentemente, da coexistência de temporalidades distintas numa mesma sociedade, não é novidade na História e na Filosofia; e, talvez, um dos exemplos mais significativos, nesse sentido, possa ser tomado em Fernand Braudel.

A História braudeliana propõe uma síntese espaço-temporal, privilegiando a duração como parâmetro da História e privilegiando a História entre as Ciências Sociais. A História, segundo ele, tem por ambição recuperar a globalidade dos fenômenos humanos, sendo a única ciência a poder localizá-los e avaliar a sua eficiência em relação a todos os saberes parcelados.

A concepção do tempo na História, de Braudel (Braudel, 1978), é pluralizada. O tempo se decompõe em muitos ritmos heterogêneos, que quebram a unidade da duração. A História, segundo ele, articula-se em três temporalidades diferentes: o factual ou tempo individual, o tempo de curta duração; o conjuntural ou social, o tempo cíclico, da média duração; e o estrutural ou geográfico, o tempo da longa duração.

Braudel procura recuperar a dialética dessas temporalidades e integrá-las em um tempo único - temporalidade global. Essas 
temporalidades, na concepção braudeliana, agem reciprocamente, mas cabe à longa duração o papel determinante.

Alfredo Bosi questiona a concepção do tempo cronológico, que busca fixar em sua simplicidade aritmética, "a polifonia do tempo social, do tempo cultural, do tempo corporal, que pulsa sob a linha de superficie dos eventos" (Bosi, 1992, p. 19). Tempo do consumismo cultural de hoje, tempo que luta contra a indiferença e a entropia. É um tempo qualificado pela presença humana, um tempo no qual a ação dos afetos e da imaginação produz uma lógica própria, capaz de construções analógicas belamente ordenadas.

É esse tempo que a arte contém e expressa, mais explicitamente, como na pintura surrealista ou em muitas músicas do século $\mathrm{XX}$, ou mais implicitamente, como na polifonia barroca, em que o cruzamento de concepções homofônicas e polifônicas, nem sempre claramente separáveis, simboliza o entrelaçamento de tempos na música, as fases e defasagens de que nos fala Wisnik (Wisnik, 1989), o emergir do futuro e o passado de Aion de Deleuze.

Memória, recorrência, tempo reversível, repetição, simultaneidade. Todas essas concepções, entrelaçadas no discurso de Bosi sobre o tempo, são muito familiares a nós, músicos, e transparecem no moteto gótico, na fuga, nas obras dodecafônicas ou na música minimalista.

Lévi-Strauss, citado por Bosi, concebe o mito e a música como máquinas de abolir o tempo, por trabalharem a fundo a reversibilidade. Estruturas musicais espelhadas, repetidas, relembradas, contrastadas, são familiares à prática musical de todos nós e dão vida à citação de Bosi. Nega-se, na verdade, no mito e na música, apenas o tempo linear...

Rima e ritmo, segundo Bosi, são procedimentos de retorno, de encurvamento, de reversibilidade interna, estrutural, formal, mas também histórica. "Na música, na poesia e na dança, o tempo é trabalhado internamente para, no conjunto, ser suspenso. Essa anulação subjetiva resulta de um processo de recorrências que despistam a serialidade das notas ou dos segmentos coreográficos. $\mathrm{Na}$ música, o efeito de simultaneidade constitui uma conquista pela 
qual o sentimento, que é difuso e abrangente, se faz energia sonora e indivisa" (Bosi, 1992, p. 29).

Indeterminação, acasos, potencialidades, latências, tempos múltiplos podem ser lidos nas linhas e entrelinhas do texto de Fayga Ostrower, Acasos e Criação Artística (p. 23), e vềm acrescentar densidade a esta proposta de uma História da Música iluminada por uma concepção tempo-significado, que é tão essencial à arte e sobretudo à música, de que se diz ser uma arte temporal. Tempos múltiplos, significados, heterogeneidade, multidirecionalidade todas estas concepções fazem parte do universo de estruturas musicais, através das quais as sociedades se expressam. Não é mais possível, por essa concepção, explicar uma forma pela outra, um autor por suas influências, seja de conjuntura ou da "herança" de outros autores. Cada obra musical temporaliza e significa, expressa e propõe, simultaneamente, intricadamente, tempos e significados múltiplos que urge abordar ao se fazer o relato histórico sobre a música.

Não cabe, por esse enfoque, explicar o romantismo como degeneração ou degradação das formas do classicismo e do tonalismo, pois no contexto de relações sociais do romantismo, as formas, ainda que aparentadas de algumas formas clássicas, são outras, significam diferentemente daquelas e só através delas mesmas podem ser explicadas. O tonalismo significa e se expressa temporalmente de forma diversa no romantismo, pois coexistem nele o código estruturado no barroco-classicismo e as novas significações desse novo tempo, que não se significa mais através da clareza dos encadeamentos dominante-tônica, mas dos rumos sinuosos que as modulações permitem. Passado e presente, se é que tais concepções significam na criação artística, entrecruzam-se e sobrepõem-se no exemplo aqui descrito.

Segundo Castoriadis (Castoriadis, 1991), é uma propriedade essencial da linguagem, enquanto sistema (e, conseqüentemente, da arte), não esgotar-se e não ser redutivel a uma totalidade fechada de significações fixas, determinadas, disponiveis, mas conter sempre a abertura à transformação das significações, a partir de recursos que encontra em si mesma. A linguagem já deve conter a 
possibilidade de novos termos, de novas significações. As dimensões sincrônica e diacrônica se entrecruzam, portanto, na linguagem; e reduzir o estudo de sua história a um desses eixos é mutilála em seus significados plenos.

Essa não-linearidade do tempo-significado, que aqui se propõe para a História da Música, implica pois a admissão da ocorrência de níveis diferentes de significação na música, em si mesma, e no social-histórico no qual ela se inscreve, significações essas regidas pelo imaginário central da sociedade. Implica também o reconhecimento de que tais significados não são fixos nem predeterminados, mas criações humanas, mutáveis, expressões de tempos variáveis que se engendram e se entrecruzam na arte. "Uma linguagem, enquantơ sistema, é impensável como pura sincronia; só é linguagem enquanto sua própria transformação incessante encontra recursos em si mesma, tal como ela é 'num certo momento'." (Castoriadis, 1991, p. 254)

Ou seja, a linguagem já deve conter, em si mesma, a possibilidade de engendramento de novos termos materiais-abstratos (sistema de significantes) e de novas significações, possibilidade esta que é imanente à sua condição de língua. E, ainda no dizer de Castoriadis, a própria linguagem, considerada "sincronicamente", é essencialmente aberta à "diacronia", pois contém a possibilidade de sua própria transformação, fornecendo, para isso, os meios parciais. "Nada, em nenhuma sociedade [o que inclui a linguagem, a língua, a arte, a música], é, que não seja, ao mesmo tempo, presença inconcebivel do que não é, mais a iminência igualmente inconcebível do que ainda não é." (Castoriadis, 1991, p. 256)

A lógica usual do pensamento ocidental, linear e causal, expressa-se também no corte em eixos sincrônicos e diacrônicos, mas a projeção da vida social-histórica sobre um de seus eixos, apenas, esvazia-a e oculta a multiplicidade e a dinâmica de suas significações, ainda que possa ser útil, em certos momentos, para explicações de caráter necessariamente segmentar. Não que as significações escapem inteiramente à lógica tradicional, mas apenas de forma restrita podem ser apreendidas por ela, pois que essa lógica não é essencialmente inerente a elas. 
Os fenômenos de sobredeterminação dos símbolos (atribuição, superposta, de significados diferentes aos mesmos significantes) e de sobre-simbolização dos sentidos (atribuição do mesmo significado a vários significantes) ilustram a superposição e a dinâmica de interação das relações de significação na linguagem, significações essas que se elaboram sobre as estruturas das significações precedentes. A rede simbólica não se constitui do "nada", mas crava-se no natural, no histórico e, conseqüentemente, no próprio simbólico que a precede - o que, contudo, não significa predeterminação nem exclui a proposição de novos simbolismos.

Chegamos, pois, nesta exposição, ao momento de retomar e melhor explicitar a concepção que aqui se defende: a da elaboração do relato da História da Música a partir de uma perspectiva prioritária de tempo-significado, com o conseqüente abandono das explicações deterministas/causais/lineares.

Tempo e significado são inseparáveis nesta proposta, como já tem sido, até aqui, abordado. Ou melhor, tempos e significados, pois o que se propõe aqui é exatamente a preservação dessa coexistência múltipla que, esquematicamente, pode ser expressa em três niveis: significados residuais (resignificados), significados atuais e significados latentes. Significação (aqui tomada como equivalente a significado) é um conceito central nessa concepção e é aqui considerada como "feixe indefinido de remissões intermináveis a outra coisa que", segundo Castoriadis (Castoriadis, 1991, p. 283).

As significações, criadoras e ordenadoras do mundo, regidas pelo imaginário central da sociedade, não podem ser pensadas independentemente de todo suporte material, pois é no fazer-dizerrepresentar de uma sociedade que elas se delineiam. E é nesse fazer-dizer-representar da sociedade que a música é uma das instâncias operativas. As estruturas e formas musicais articulam sentidos e significações e, como tal, é essencial que sejam apreendidas no relato histórico.

Os modos de ordenação das estruturas e formas musicais expressam e propõem significações, posto que a música, como qualquer outra forma de linguagem, não opera com um universo fixo de significados; e contém em si mesma a possibilidade de novas 
ordenações e significações. Ou seja, os signos utilizados na linguagem musical reportam-se à rede simbólica presente no momento histórico de sua elaboração, mas também podem ser investidos de outras significações que não correspondam a esse mesmo momento histórico, assim como podem portar, residualmente, significados elaborados em momentos históricos outros e que, portanto, estão sendo utilizados através de um processo de resignificação.

É aqui que se inserem os três niveis de significados concebidos como inerentes à música e, portanto, necesșários à elaboração de qualquer relato histórico sobre ela.

Mas, como foi dito anteriormente, a música, como qualquer linguagem, não se restringe a um universo fixo de significações e contém também latências e resíduos de significações (resignificados). Significados residuais, aqui, são concebidos como resignificados, pois que não é possível à sociedade apropriar-se, de maneira idêntica, de significados elaborados fora de sua realidade (significados remanescentes de outras épocas ou contextos). Os signos, portadores desses significados, quando reutilizados por outra época ou contexto, são dotados de novas significações, pertinentes à atualidade da sociedade considerada, pertinentes à realidade operante em que são utilizados. Assim, apesar da aparente identidade, esta é apenas externa, ao nível do suporte material do processo simbólico, pois o nível de significações passou por uma transformação, fruto da capacidade dinâmica de qualquer linguagem.

Toda sociedade porta resíduos, pois não pode ser concebida apenas como a instituição do novo a cada momento. Sua própria unidade estaria, nesse caso, comprometida. Contudo, é importante que seja reconhecida a ocorrência das modificações, dos deslocamentos de significados, para que não ocorram distorções na interpretação desses resíduos.

Jacques Attali (1977) define a música como metáfora credível do real e considera que ela não é nem uma atividade autônoma, nem uma implicação automática da infraestrutura econômica. A música, segundo ele, é anúncio, porque a mudança se inscreve mais rapidamente no ruido que na sociedade. Attali realça as relações da música com o poder e como o poder sempre se viu obrigado a 
controlá-la, pois ela, além de refletir a sociedade, contém a possibilidade de subvertê-la através da proposição de outras ordens, sentidos e significados que não os presentes ou desejáveis. Attali enfatiza também as sintaxes mutáveis da música e critica a visão progressiva da tradição musicológica, que concebe uma música que evolui de primitiva a clássica e a moderna. Esquema, segundo ele, ultrapassado em todas as ciências humanas, para as quais a busca de uma evolução estruturada linearmente é ilusória. A música, segundo ele, não evolui linearmente, mas imbricada na complexidade e na circularidade dos movimentos da História.

Enfatizando ainda o caráter "profético" da música, Attali afirma que os ruídos de uma sociedade são avançados em relação às imagens e aos conflitos materiais. Profética a música, no sentido de que cria novas ordens, instáveis e mutáveis, através de códigos que não podem ser pensados como uma sucessão temporal correspondente a uma sucessão de relações econômicas, porque o tempo atravessa a música e a música dá sentido ao tempo. "A simultaneidade de códigos múltiplos, com interpenetração móvel entre os períodos, os estilos e as formas impede toda genealogia da música, toda arqueologia hierárquica, toda localização ideológica precisa de um músico, (...) [que é essencialmente] inovador e anunciador de mundos futuros." (Attali, 1977, p.35) Atalli cita também LéviStrauss e compara a ordem na música com a ordem nos mitos, considera-a memória coletiva e organizada da sociedade, forma de conhecimento, ritual simbólico e prenúncio das mudanças sociais.

O texto de Attali vem ao encontro das proposições até aqui formuladas para a música e para sua História: a música expressa, significa, resignifica, antecipa, em suas estruturas e formas, significados residuais, atuais e latentes, numa dinâmica não-linear, nãoapreensível pela lógica tradicional, posto que primordialmente sujeita à lógica do imaginário.

Dissemos, no início desta conferência, que a História é um relato interpretativo, feito por um sujeito histórico, e necessariamente impregnado dos significados e percepções de sua epoca.

A História da Música tem sido feita, salvo algumas exceções, com o olhar europeu do século XIX. Os significados têm sido ne- 
gados explicita ou implicitamente em seu discurso, ou reduzidos à determinação do social-econômico, à concepção causal, à lógica tradicional. A realidade dos paises colonizados tem sido freqüentemente desconsiderada, quando a maioria dos estudos a analisa pela ótica européia e termina por concluir de seu atraso ante os centros "adiantados".

Foi, particularmente, pensando numa musicologia brasileira que a presente concepção foi elaborada. Pois, ao privilegiar o enfoque do tempo-significado, ao conceber a multiplicidade interativa e dinâmica de significados latentes, presentes ou residuais (resignificados), buscou-se exatamente valorizar o que essa música elabora significados residuais, advindos da cultura européia, negra ou india, aqui revestidos de novos significados, significados presentes, superpostos ou cravados nos anteriores, que refletem o momento vivido nessa sociedade; e significados latentes, novas ordenações que a música, com a liberdade que o imaginário lhe concede, está sempre a propor à sociedade.

A presença da rítmica negra ou do tonalismo europeu, ou da modinha e de elementos da ópera européia numa mesma obra adquire nova configuração, a partir dessa iluminação a obra do padre José Mauricio não é "atrasada" em relação a Beethoven; ela significa diferente, simboliza diferente, propõe diferente, pois que elaborada em outro contexto de significações sociais. Os compositores brasileiros do século XX não estão "atrasados" em relação aos europeus ou americanos, que dominam de forma mais "avançada" as conquistas da linguagem musical universal. Nem tampouco a sonata clássica de Haydn ou Mozart, interpretada por Schurmam ou Wisnik como simbolização das relações sociais, num contexto de ascensão da burguesia, pode ser restrita a essa ótica, pois que nela persistem resíduos estruturais do barroco, resignificados do classicismo e latências de períodos posteriores.

Tempo fluido, tempo criação, reversivel e irreversível, tempo de acasos, tempo musical. O moteto gótico é um exemplo explícito dessa convivência temporal múltipla, quando associa o tempo da igreja e o profano, os textos latinos e em língua vernácula, quando é construído com elementos musicais que retornam, expandem-se, 
revertem, superpõem-se, espelham-se, contradizem-se e afirmamse. Explícito no moteto ou em diversas tendências da música no século XX; por exemplo, implícito em outras expressões musicais, esse tempo múltiplo pulsa e significa na música, presentificando significados, articulados com o momento social-histórico, resignificando elementos que foram articulados em outros presentes, projetando significados, que no momento são latências, mas que se tornarão presenças

As formas, na arte, são cristalizações de significados, no sentido de concretização deles; e a História da Arte não se desprende delas, na medida em que é através das formas dadas que o historiador pode tentar apreender a História. Mas não pode interpretar essa cristalização no sentido do imobilismo, ou de nexo causal, na ilusão de poder explicar o "agora" pela longa cadeia dos "antes". Se, por um lado, a História está irremediavelmente ligada à concretude, não há por que reduzir-se a ela.

A abordagem aqui proposta não exclui a possibilidade de densidades maiores ou menores, e irregulares, desses niveis de significação, ou até mesmo a possibilidade de rupturas totais com o passado, com a evidência apenas de significados presentes e latentes. Contudo, só o retorno dessa concepção à prática da História da Música pode dar respostas advindas da análise dos diferentes momentos.

Basicamente, as principais possibilidades advindas da utilização da concepção aqui apresentada à prática da História da Música são: $1 .{ }^{\circ}$ ) a concepção da música como linguagem portadora de significados sociais e apreendida na explicação histórica, a partir da ênfase nos aspectos significativos; 2.") a valorização da significação atual, ainda que elaborada sobre formas e estruturas de outra época ou contexto, rompendo com as explicações causais, como as de "degeneração" de um sistema, ou de "atraso"; 3.) a ruptura com a ênfase no tempo linear, privilegiando a multiplicidade de articulações temporais e, conseqüuentemente, de significações numa mesma obra e num mesmo contexto; $4^{\circ}$ ) a ruptura com o enfoque determinista, ou de geração causal, a partir da valorização do imaginário como estruturador central das significações; $5^{\circ}$ ) a preser- 
vação de concepções teóricas importantes, já consagradas no curso da História, como as de ideologia ou classe social, sem contudo restringi-las a uma visão determinista; 6 .") a concepção de obra e contexto como instâncias intrincadas, inseparáveis; 7.") a captação da música como fenômeno social, dinâmico, significativo, como elemento expressivo e estruturador da sociedade em que se insere.

Duas citações de Felix Guattari (Guattari, 1992, p. 129) parecem úteis para finalizar esta conferência. Na primeira, ele cita Marcel Duchamp, que declara que "a arte é um caminho que leva para regiões que o tempo e o espaço não regem”. Essa multiplicidade espaço-temporal inerente à música está presente na proposta aqui apresentada, resgatada a partir de uma concepção de tempo-significado aplicada à criação musical e ao relato sobre ela

A segunda, é de que "toda leitura do passado é necessariamente sobrecodificada por nossas referências do presente". A História, leitura do passado do homem por um homem histórico, traz necessariamente essas referências de seu tempo; e a ciência e a filosofia do século $X X$, que têm resignificado as concepções de tempo e espaço, não podem deixar de impregnar o nosso olhar prospectivo. O tempo múltiplo e as significações, temáticas importantes da atualidade, podem nos trazer novas percepções e talvez mais ricas da História da Música e mais coerentes com o universo conceitual de nossa época, que já não teme formular uma teoria do Caos como reorientação para a ciência, ou de rever a sabedoria dos mitos, das explicações místicas e da arte. 


\section{BIBLIOGRAFIA}

ABBAGNANO. Nicola. Dicionário de Fillosofia. São Paulo. Mestre Jou. 1970. ATTALI. Jacques, Bruits. Vendôme. Presses Universitaires, 1977.

BACHELARD. Gaston. Al dialética da duração. São Paulo. Ática. 1988. BOSI. Alfredo O tempo e os tempos In: Tempo e História. São Paulo. Companhia das Leiras. 1992.

BRAUDEL. Fernand Escritos sohre história. São Paulo. Perspectiva. 1978. CASTORIADIS, Cornclius I instituição imaginária da sociedade. Rio de Janciro. Paz c Terra. 1991.

DELEuze, Giles. Lógica do sentido. São Paulo. Perspectiva. 1974.

GUATTARI, Felix Caosmose. L'm novo paradigma estético. Rio de Janeiro. Editora 34. 1992

HADJINICOLAOU, Nicos. História da arte e movimentos sociais, Lisboa. Edições 70. 1989.

LORAUX. Nicole. O clogio do anacronismo. In: Tempo e Ifistoria. São Paulo. Companhia das Letras. 1992.

OSTROWER. Fayga Acasos e criação artística. Rio de Janciro. Campus. 1990 .

WISNIK. José Miguel. O som e o sentido. São Paulo. Companhia das Letras/ Círculo do Livro. 1989.

\section{NOTAS}

1 Santo Agostinho considera que não existem. propriamente falando. três tempos: o passado, o presente e o futuro, mas somente três presentes: o presente do passado. o presente do presente e o presente do futuro. concepção essa que enfatiza a percepção do tempo através do presente.

2 Cfr. dados sobre Newton, Bergson e Heidegger $\mathrm{cm}$ : Nicola ABBAGNANO. Dicionário de Filosofia. 1970

Vanda Lima Bellard Freire é Professora Titular de História da Música da Escola de Música da Universidade Federal do Rio de Janeiro. 